\title{
Potencial agroclimático para a cultura da acerola no Estado de Minas Gerais
}

\author{
Maria J. H. de Souza ${ }^{1}$, Marilaine C. A. Guimarães ${ }^{2}$, Carlos D. L. Guimarães ${ }^{3}$, Wallisson da S. Freitas ${ }^{4}$ \& Ângelo M. S. Oliveira ${ }^{3}$
}

\section{RESUMO}

Objetivou-se realizar o zoneamento agroclimático do Estado de Minas Gerais, visando dar subsídios à seleção de locais para a implantação da cultura da acerola (Malpighia glabra L.). Utilizaram-se dados de temperatura média e precipitação de 110 estações meteorológicas de Minas Gerais e de Estados circunvizinhos; com base nesses dados calculou-se 0 índice de umidade de Thornthwaite \& Mather para uma capacidade de armazenamento de água no solo de $125 \mathrm{~mm}$. Elaboraram-se mapas de aptidão térmica e hídrica, a partir da temperatura média e do índice de umidade, para essa cultura, com a sobreposição dos mapas, obteve-se o mapa de aptidão agroclimática do Estado para a cultura da acerola. Cerca de $12,6 \%$ do território de Minas Gerais, região sul, e uma pequena parte da região central, são inaptos para o cultivo da aceroleira, devido à ocorrência de baixas temperaturas. Em 55,8\% do Estado observam-se condições favoráveis para o cultivo da aceroleira enquanto em $4,5 \%$ as condições são regulares. Áreas com aptidão restrita compreendem $27 \%$ do Estado, sendo que em $18 \%$ o cultivo é recomendado somente com o emprego de irrigação, devido à restrição hídrica, enquanto nos outros 9\% o cultivo é limitado pelo excedente hídrico.

Palavras-chave: Malpighia glabra L., fruticultura, aptidão agroclimática, aptidões hídrica e térmica

\section{Agroclimatic potential for the West Indian Cherry cropping in the State of Minas Gerais}

\begin{abstract}
This study aimed to accomplish the agroclimatic zoning of Minas Gerais State, in order to provide subsidies for selection of areas for implantation of the West Indian Cherry (Malpighia glabra L.) crop. The average temperature and precipitation data relative to 110 meteorological stations located in Minas Gerais and surrounding states were used. Based on these data, the moisture index by Thornthwaite \& Mather for a soil water storage capacity of $125 \mathrm{~mm}$ was calculated. The thermal and hydric aptitude maps were drawn for the crop from the average temperature and moisture index. The State agroclimatic aptitude map was obtained by superposing these maps. It was found that only $12.6 \%$ of the state territory, south region and a small portion of the central region are inapt for the cultivation of the West Indian Cherry, because of low temperatures in this region. Favorable conditions for this crop are found in $55.6 \%$ of the State area, whereas $4.5 \%$ show regular conditons. The areas showing regular aptitude occupy $27 \%$ of the state territory, but the crop is only recommended with irrigation for $18 \%$ from this total, because of water restriction, whereas it is restrained by excess water in the remaining $9 \%$ areas.
\end{abstract}

Key-words: Malpighia glabra L., fruit growing, agroclimatic aptitude, hydric and thermal aptitudes

1 Departamento de Agronomia, Faculdades Federais Integradas de Diamantina, CEP 39100-000, Diamantina, MG. Fone: (38) 3532 1200. Email: mariahatem@yahoo.com.br, mjhatem@ufv.br

${ }_{2}^{2}$ Petrobras - S. A., Rodovia BR 110, Km 378, Base Taquipe, CEP43850-000, São Sebastião do Passé, BA. Fone: (71) 3642 5306. E-mail: marilainearaujo@yahoo.com.br, marilaine@petrobras.com.br

${ }_{3}^{3}$ Departamento de Engenharia Florestal, UFV. CEP 36571-000, Viçosa, MG. Fone: (31) 3899 2477. E-mail: cdlguimaraes@yahoo.com.br, angelomarcos@vicosa.ufv.br ${ }_{4}^{4}$ Departamento de Engenharia Agrícola, Universidade Federal de Viçosa, CEP 36571-000, Viçosa, MG. Fone: (31) 3899 1888. E-mail: mjhatem@ufv.br, wallfreitas@yahoo.com.br 


\section{INTRODUÇÃO}

No planejamento e programação das atividades rurais, uma ferramenta importante é a avaliação do potencial agroclimático das áreas, conforme a necessidade das culturas. O zoneamento agroclimático auxilia na tomada de decisão dos produtores rurais, que visam a um aproveitamento melhor dos recursos naturais da propriedade, além de orientar ações de prefeituras que pretendam incentivar a agropecuária em seu município (Assad, 1998).

A fruticultura representa papel relevante na economia nacional. O Brasil é um dos três maiores produtores mundiais de frutas (cerca de 39 milhões de toneladas por ano), exportando pouco mais de $1 \%$ da sua produção in natura, ocupando o $20^{\circ}$ lugar entre os países exportadores, segundo dados do Ministério da Agricultura (AGRIANUAL, 2002).

Outro aspecto de grande relevância na fruticultura é sua importância social, visto que em se tratando de cultivo extensivo e intensivo, exige a presença constante do agricultor e requer mão-de-obra em grande escala; além de se tratar de um fator de fixação do homem no campo, eleva o seu padrão de vida, cuja função se estende além dos campos, pela integração de mão-de-obra na comercialização, distribuição, venda e industrialização dos produtos (Simão, 1971).

O interesse dos produtores e do mercado consumidor da cultura de acerola (Malpighia glabra L.) surgiu em razão do alto teor de vitaminas e compostos benéficos do fruto, como os antioxidantes, descobertos por Ansejo (1959). Os carotenóides presentes na acerola podem fornecer 720 a 4.540 unidades internacionais de vitamina A por 100 gramas de fruto, enquanto a concentração de vitamina $C$ pode variar entre 1.325 e $2.250 \mathrm{mg}$ por $100 \mathrm{~mL}$ de suco (Gonzaga Neto \& Soares, 1994).

Nos países em desenvolvimento, como o Brasil, que apresentam grande contingente populacional de baixa renda, a cultura de acerola exerce significativo papel social, devido à possibilidade de contribuir para a melhoria de qualidade da nutrição e da saúde da população.

No Brasil, esta planta foi introduzida, oficialmente, em 1955, na região Nordeste, através da Universidade Federal Rural de Pernambuco, com sementes trazidas de Porto Rico (Simão, 1971); entretanto, segundo Andrade et al. (1995) o cultivo da aceroleira adquiriu escala comercial somente na década de 80, sendo pioneiros os estados da Bahia e do Pará, que visavam à exportação da acerola para a Europa e o Japão.

Os preços de acerola no atacado, segundo dados do CEAGESP (2003), para o mês de maio de 2003, variaram entre 6,00 e 6,66 reais por quilo. De acordo com dados coletados no AGRIANUAL (2002), a renda líquida, na época em que a manutenção da produção é estável, ou seja, do quinto ao décimo ano de produção, atinge 8.087 dólares por hectare mostrando, assim, a importância econômica desta cultura.

A acerola é uma fruta de origem tropical, proveniente da região do Caribe, onde é conhecida como cereja das Antilhas. Segundo Araújo \& Minami (1994), a aceroleira requer temperaturas médias anuais em torno de 25 a $27{ }^{\circ} \mathrm{C}$, apresentando ótimo desenvolvimento em regiões tropicais ou subtropicais.
Em relação à precipitação, a aceroleira apresenta desenvolvimento adequado, em áreas com precipitação anual em torno de 1.800 mm (Argles, 1988, citado por Araújo \& Minami, 1994). Quando os totais anuais de precipitação ultrapassam 2.000 mm e não há boa drenagem no solo, os frutos se tornam aquosos, mais frágeis, menos ricos em açúcares, apresentando qualidade inferior; entretanto, quando os totais anuais de precipitação são inferiores a $1.200 \mathrm{~mm}$, os frutos produzidos são pequenos, enrugados e apresentam baixo teor de ácido ascórbico (Teixeira \& Azevedo, 1994). Nakasone et al. (1996) verificaram, no Havaí, a existência de um acréscimo no teor de ácido ascórbico proporcional à quantidade de radiação solar absorvida pela cultura.

Para Rieger (1976) citado por Teixeira \& Azevedo (1994), a aceroleira é muito resistente à seca e se apresenta como caducifólia, sob condições de elevada deficiência hídrica, porém, ressaltam reduções significativas na produtividade da cultura sob condições de elevada deficiência hídrica.

Teixeira \& Azevedo (1994) ao estudarem o potencial agroclimático da cultura da acerola para o estado de Pernambuco, empregaram os índices de umidade (Im) de Thornthwaite \& Mather (1955) como limitadores hídricos e uma capacidade de armazenamento de água no solo de $125 \mathrm{~mm}$. Os autores consideraram como áreas de aptidão hídrica plena, as que possuíam Im entre -15 e $55 \%$, as de aptidão regular com Im entre -25 e $-15 \%$, restrita com Im superior a 55\% e as áreas inaptas as que possuíam Im inferior a -25\%. Posteriormente, outros autores empregaram esses mesmos índices como limitadores hídricos, ao realizarem o zoneamento da acerola para os estados do Piauí (Viana et al., 2002) e da Bahia (Cecílio et al., 2004).

No Brasil, a cultura da acerola oferece grandes possibilidades de sucesso, devido às condições climáticas favoráveis, principalmente na parte tropical do território nacional e pelo aspecto nutricional para a saúde pública, particularmente das populações economicamente mais carentes.

Ante o exposto objetivou-se, no presente trabalho, realizar o zoneamento agroclimático do Estado de Minas Gerais, visando dar subsídios à seleção de locais para a implantação da cultura da acerola (Malpighia glabra L.).

\section{MATERIAL E MÉTODOS}

O presente trabalho foi conduzido em duas etapas: (1) elaboração dos mapas de aptidão térmica e aptidão hídrica do Estado de Minas Gerais para a cultura da acerola; e (2) sobreposição dos mapas de aptidão térmica e aptidão hídrica para geração do mapa de aptidão agroclimática do Estado.

O Estado de Minas Gerais apresenta grande diversidade climática (Antunes, 1986), com quatro tipos climáticos principais: tropical úmido de savana (Aw), clima seco com chuvas no verão (BSw), temperado chuvoso (Cwa) e subtropical de altitude (Cwb), conforme classificação climática de Köppen (Vianello \& Alves, 1991; Costa, 1994; Pereira et al., 2002). Esta diversidade climática possibilita o cultivo de diferentes espécies vegetais temperadas a tropicais, no Estado, desde plantas de ciclo curto, como as hortaliças, até fruteiras de ciclo longo. 
As informações climáticas do Estado de Minas Gerais foram obtidas no banco de dados da Empresa Brasileira de Pesquisa Agropecuária (EMBRAPA), disponibilizado na mídia CBPDC (2002). Os dados foram previamente avaliados quanto à qualidade e consistência.

Utilizaram-se dados climáticos de temperatura e precipitação mensal, relativos a 110 estações meteorológicas do Estado de Minas Gerais e estados circunvizinhos (Figura 1). Deste total, dados de 46 estações são provenientes do Instituto Nacional de Meteorologia (INMET/MAPA), sendo os demais oriundas da Agência Nacional de Energia Elétrica (ANEEL). A partir desses dados calculou-se o balanço hídrico de Thornthwaite \& Mather (1955) e os índices de umidade (Im) para cada localidade; para tal empregou-se uma capacidade de armazenamento de água no solo de $125 \mathrm{~mm}$, valor este recomendado por Teixeira \& Azevedo (1994) para a cultura da acerola.

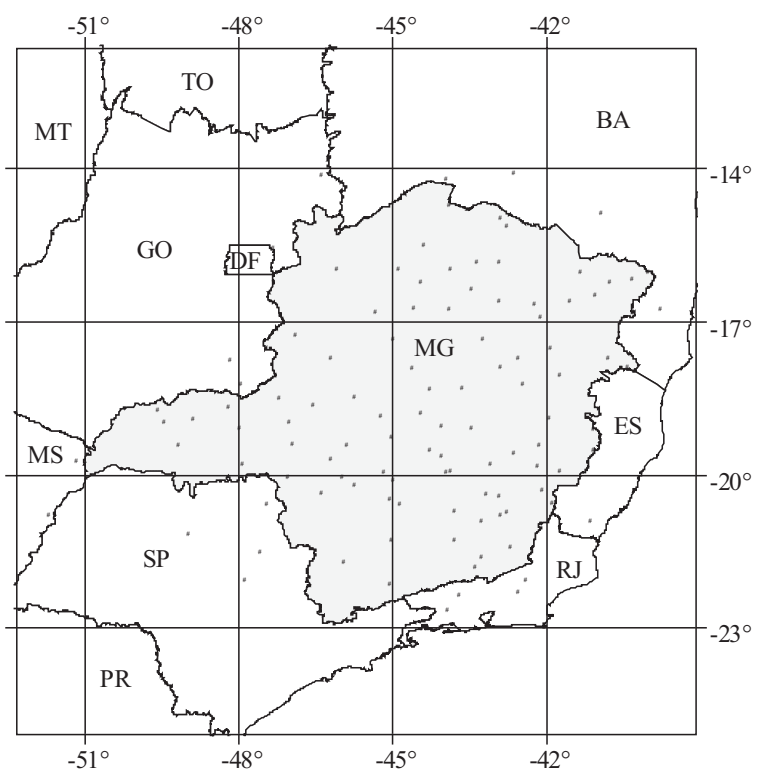

Figura 1. Localização das estações meteorológicas

Os índices de umidade de Thornthwaite \& Mather (1955) foram calculados pelas equações abaixo:

$$
\begin{gathered}
\mathrm{Ih}=100 \frac{\mathrm{EXC}}{\mathrm{ETP}} \\
\mathrm{Ia}=100 \frac{\mathrm{DEF}}{\mathrm{ETP}} \\
\mathrm{Im}=\mathrm{Ih}-\mathrm{Ia}
\end{gathered}
$$

em que: Ih é o índice hídrico, em \%, Ia é o índice de aridez, em \%, Im é o índice de umidade, em \%, EXC é o excedente hídrico anual, em mm, DEF é a deficiência hídrica anual, em mm, e ETP a evapotranspiração potencial anual, em mm.

Realizou-se o zoneamento agroclimático com base nas informações de índice de umidade e temperatura média anual. As classes de aptidão térmica e hídrica do Estado para o cultivo da aceroleira, foram definidas conforme apresentado na Tabela 1.

Temperaturas iguais ou superiores a $26^{\circ} \mathrm{C}$, não ocorrem em Minas Gerais, razão pela qual não se adotou classe de aptidão térmica acima deste valor, não indicando que a cultura não desenvolva bem em locais em que a temperatura média anual seja superior a $26^{\circ} \mathrm{C}$, como é o caso do nordeste.

Os dados de temperatura média anual e índices de umidade foram empregados para gerar os mapas de aptidão térmica e hídrica, respectivamente, através do software ArcView ${ }^{\circledR}$ versão 3.2, e do interpolador IDW (inverso do quadrado da distância) com a potência 4, por ser um dos mais aconselhados. O mapa de aptidão climática do Estado de Minas Gerais para o cultivo da aceroleira, foi obtido a partir da sobreposição dos mapas de aptidão térmica e hídrica, disponibilizada no software. As classes de aptidão climática são apresentadas na Tabela 2, enquanto a seqüência dos procedimentos adotados é apresentada no fluxograma da Figura 2.

Tabela 1. Classes de aptidão térmica e hídrica, com base na temperatura média anual e no índice de umidade

\begin{tabular}{|c|c|c|}
\hline Aptidão & Aptidão & Descrição das classes \\
\hline \multirow{3}{*}{ APTA } & APTA 1 & $\begin{array}{l}\text { Áreas que apresentam condições ótimas para o cultivo da aceroleira, ou seja, que propiciam à cultura um ambiente plenamente favorável } \\
\text { para o seu crescimento e desenvolvimento no que se refere à exigência térmica e disponibilidade de água. Temperatura média anual entre } \\
24 \text { e } 26^{\circ} \mathrm{C} \text { e índice de umidade entre }-15 \text { e } 55 \% \text {. }\end{array}$ \\
\hline & APTA 2 & $\begin{array}{l}\text { Áreas que apresentam boas condições para o cultivo da aceroleira, ou seja, temperatura média anual entre } 22 \text { e } 24^{\circ} \mathrm{C} \text { e índice de umidade } \\
\text { entre }-15 \text { e } 55 \% \text {. }\end{array}$ \\
\hline & APTA 3 & $\begin{array}{l}\text { Áreas que apresentam condições para o cultivo da aceroleira, ou seja, temperatura média anual entre } 20 \text { a } 22{ }^{\circ} \mathrm{C} \text { e índice de umidade entre } \\
-15 \text { e } 55 \% \text {. }\end{array}$ \\
\hline \multirow{3}{*}{ REGULAR } & REGULAR 1 & $\begin{array}{l}\text { Áreas com pequena restrição hídrica e ótimas condições térmicas, necessitando de irrigação suplementar, ou seja, com temperatura entre } \\
24 \text { a } 26^{\circ} \mathrm{C} \text { e índice de umidade entre }-25 \text { e }-15 \% \text {. }\end{array}$ \\
\hline & REGULAR 2 & Áreas com pequena restrição térmica, com temperatura entre 22 e $24^{\circ} \mathrm{C}$ e índice de umidade entre -25 e $-15 \%$. \\
\hline & REGULAR 3 & $\begin{array}{l}\text { Áreas restrição térmica moderada e pequena restrição hídrica, necessitando de irrigação suplementar, ou seja, com temperatura entre } 20 \text { e } \\
22^{\circ} \mathrm{C} \text { e índice de umidade entre }-25 \text { e }-15 \% \text {. }\end{array}$ \\
\hline \multirow[t]{2}{*}{ RESTRITA } & & $\begin{array}{l}\text { Áreas com grandes restrições hídricas (índice de umidade inferior a }-25 \% \text { ) e boas condições térmicas, sendo possível o cultivo de acerola } \\
\text { com o uso da irrigação suplementar, em áreas com temperaturas superiores a } 20{ }^{\circ} \mathrm{C} \text {. }\end{array}$ \\
\hline & & Áreas com índice de umidade superior a $55 \%$ e temperatura superior a $20^{\circ} \mathrm{C}$. \\
\hline INAPTA & INAPTA & Áreas com restrições térmicas severas, com temperatura inferior a $20^{\circ} \mathrm{C}$. \\
\hline
\end{tabular}

\begin{tabular}{cccc}
\hline $\begin{array}{c}\text { Temperatura } \\
\text { média anual, } \\
\mathrm{T}_{\mathrm{a}}\left({ }^{\circ} \mathrm{C}\right)\end{array}$ & Aptidão térmica & $\begin{array}{c}\text { Índice de } \\
\text { umidade, } \\
\text { Im (\%) }\end{array}$ & Aptidão hídrica \\
$\mathrm{T}_{\mathrm{a}}<20$ & Inapta & $\operatorname{Im}<-25$ & Inapta \\
$20 \leq \mathrm{T}_{\mathrm{a}}<22$ & Apta (A3) & $-25 \leq \mathrm{Im}<-15$ & Regular \\
$22 \leq \mathrm{T}_{\mathrm{a}}<24$ & Apta (A2) & $-15 \leq \mathrm{Im}<55$ & Apta \\
$24 \leq \mathrm{T}_{\mathrm{a}}<26$ & Apta (A1) & $\operatorname{Im} \geq 55$ & Restrita \\
\hline
\end{tabular}

Tabela 2. Classes de aptidão para o cultivo da aceroleira em Minas Gerais 


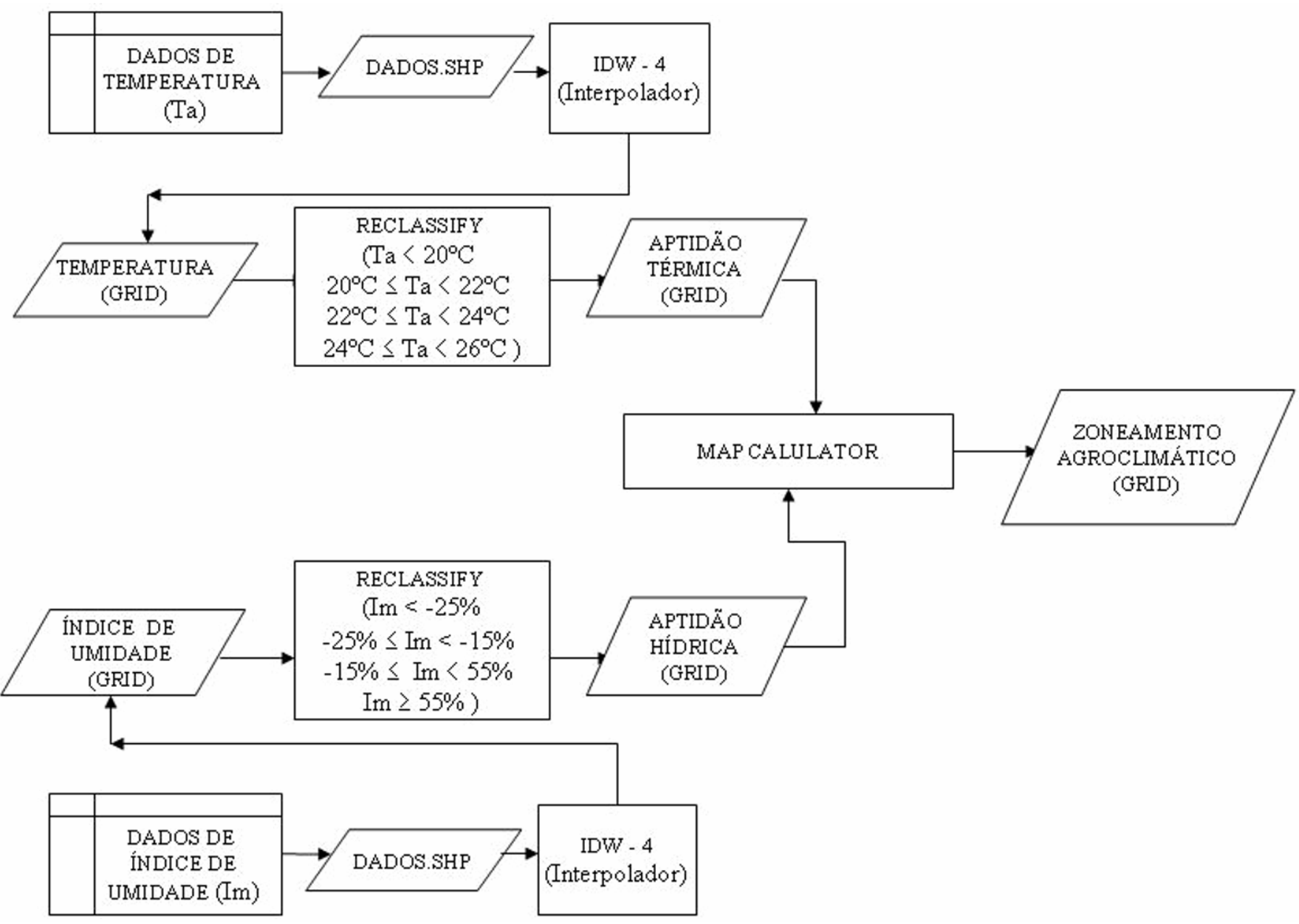

Figura 2. Fluxograma de geração do mapa de aptidão climática do Estado de Minas Gerais, para a cultura da acerola

\section{RESULTADOS E DISCUSSÃO}

A distribuição da temperatura média anual, da precipitação e do índice de umidade no Estado de Minas Gerais são mostradas na Figura 3, na qual se observa que as temperaturas mais baixas se localizam na região sul do Estado devido a menores latitudes e maiores altitudes, em conseqüência da presença da Serra da Mantiqueira - e também na região do Parque Estadual do Pico do Itambé, onde se encontra o Pico do Itambé (2002 m de altitude). As temperaturas mais altas se encontram nas regiões norte e nordeste do Estado, por serem observadas, nesses locais, as menores altitudes e latitudes. Temperaturas iguais ou superiores a $26{ }^{\circ} \mathrm{C}$ não ocorrem no estado.

Nota-se, na Figura 3, as áreas com maior precipitação anual estão presentes no sul do Estado, enquanto as menores precipitações ocorrem no norte e nordeste do Estado. Ainda nesta figura observa-se que os maiores valores de índice de umidade ocorrem na região sul do Estado e em parte das regiões central e oeste do estado. Valores negativos de índices de umidade são observados principalmente nas regiões norte e nordeste do estado, em conseqüência da alta demanda evaporativa das regiões, as quais apresentam as temperaturas mais elevadas do estado, com menores valores de precipitações, resultando em uma deficiência hídrica que supera o excedente hídrico; conseqüentemente, os valores de índices de umidade são negativos.

Os mapas de aptidões térmica, hídrica e agroclimática para a cultura da acerola, no estado de Minas Gerais são apresentados na Figura 4. Observa-se, na Figura 4, que do ponto de vista térmico a região sul e uma pequena parte da região central (região do Parque Estadual do Pico do Itambé) são inaptas para o cultivo da acerola (12,6\% do estado); no entanto, o restante do estado apresenta condições de aptidão, sendo que as áreas consideradas com aptidão 1 (A1), temperatura média anual entre 24 e $26^{\circ} \mathrm{C}$, se encontram no norte e nordeste do estado, totalizando $14,8 \%$. Áreas com aptidão 2 (A2), temperatura entre 22 e $24{ }^{\circ} \mathrm{C}$, ocorrem na maior parte do estado, principalmente no triângulo mineiro, parte das regiões central e leste, representando 40,2\% da área do estado. Já as áreas com aptidão térmica 3 (A3), temperaturas entre 20 e $22{ }^{\circ} \mathrm{C}$, ocorrem, sobretudo, em parte das regiões central e sudeste do estado, ou seja em 32,4\% do estado.

Nota-se na Figura 4 que 18\% da área do estado são inaptos, do ponto de vista hídrico, para o cultivo da acerola (possuem índice de umidade inferior a -25\%); estas áreas se concentram no norte e nordeste do estado, e do ponto de vista térmico, apresentam aptidão A1 (Figura 4), portanto nelas a acerola poderá ser cultivada, para fins comerciais, com o 


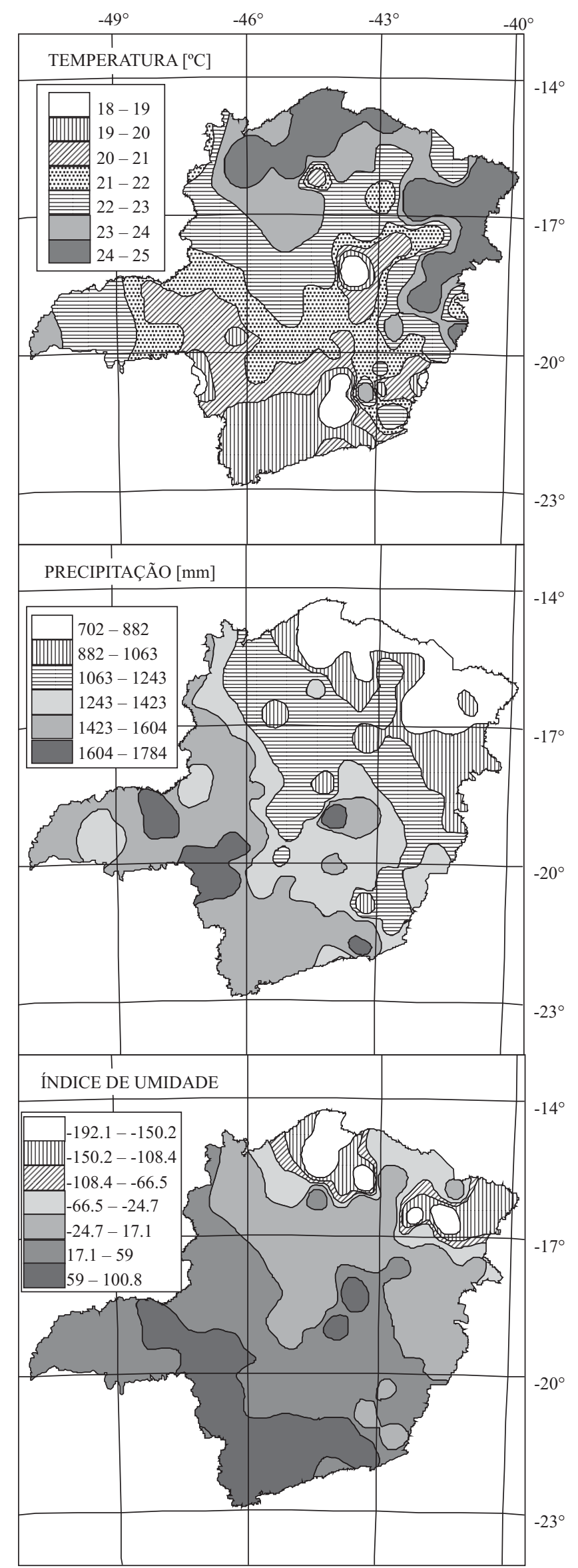

Figura 3. Temperatura média anual, em ${ }^{\circ} \mathrm{C}$, precipitação total anual, em $\mathrm{mm}$, e índice de umidade no Estado de Minas Gerais emprego da irrigação. Áreas com aptidão hídrica regular representam apenas $4,5 \%$ do estado (índice de umidade entre -25 e -15\%), enquanto áreas com aptidão restrita totalizam 20,1\%; nesta área, o índice de umidade é superior a 55\% e a cultura poderá apresentar problemas relacionados ao excesso de água no solo. Áreas com aptidão hídrica (índices de umidade entre -15 e 55\%) somam 57,4\% da área do estado, e se concentram principalmente na região central do estado e em parte do triângulo mineiro.

No mapa de aptidão agroclimática (Figura 4) nota-se que as áreas aptas representam 55,8\% da área do estado, sendo que áreas com aptidão 1 (temperatura média anual entre 24 e $26{ }^{\circ} \mathrm{C}$ e índice de umidade entre -15 e $55 \%$ ) totalizam apenas $1,6 \%$ da área do estado, localizando-se no leste do estado; áreas com aptidão 2 (temperatura média anual entre 22 e $24{ }^{\circ} \mathrm{C}$ e índice de umidade entre -15 e $55 \%$ ) somam $30,8 \%$ do estado e se concentram na região do triangulo mineiro, em parte do leste, do noroeste e na região central do estado; e aptidão 3 (temperatura média anual entre 20 a $22{ }^{\circ} \mathrm{C}$ e índice de umidade entre -15 e 55\%) compreendem 23,4\% do território do estado localizando-se ao sul e à leste das áreas com aptidão 2.

Áreas com aptidão agroclimática regular englobam apenas 4,5\% da área do estado (são áreas com pequenas restrições hídricas ou térmicas, conforme indicado na Tabela 2), concentrando-se, em pequena parte, as regiões leste e norte do estado.

Com relação às áreas com restrição agroclimática para o cultivo da acerola, estas totalizam $27 \%$ da área do estado, sendo que $9 \%$ têm restrição 2 (índice de umidade superior a $55 \%$ e temperatura média anual superior a $20{ }^{\circ} \mathrm{C}$ ), ou seja, restrição térmica moderada e índice de umidade elevado, podendo a cultura apresentar problemas relacionados com o excedente hídrico no solo e os frutos se tornam aquosos, mais frágeis, menos ricos em açúcares, apresentando qualidade inferior (Argles, 1988, citado por Araújo \& Minami, 1994); essas áreas se localizam principalmente no sudoeste do estado. $18 \%$ são referentes às áreas com grandes restrições hídricas, Im menor que -25\%, e boas condições térmicas (área denominada no mapa de restrita 1) e se concentram no norte e nordeste do estado, sendo o cultivo comercial recomendado com o uso da irrigação suplementar. Embora apresentando aptidão térmica ideal ou regular, conforme se observa na Figura 4, referidas áreas apresentam déficit hídrico elevado. Apesar da aceroleira ser muito resistente à seca e se apresentar como caducifólia, sob condições de elevada deficiência hídrica, porém, ressaltam reduções significativas na produtividade da cultura (Rieger, 1976, citado por Teixeira \& Azevedo, 1994), podendo os frutos serem pequenos, enrugados e de baixo teor de ácido ascórbico (Teixeira \& Azevedo, 1994).

Em locais de déficit hídrico elevado o cultivo comercial da aceroleira é recomendado somente com a utilização de irrigação, isto representa uma vantagem pois, com o uso da irrigação, a produção pode ser programada, para que a colheita coincida com a época de entressafra, quando os preços da fruta fresca são mais elevados (AGRIANUAL, 2002).

Nas áreas em que a disponibilidade hídrica é adequada 


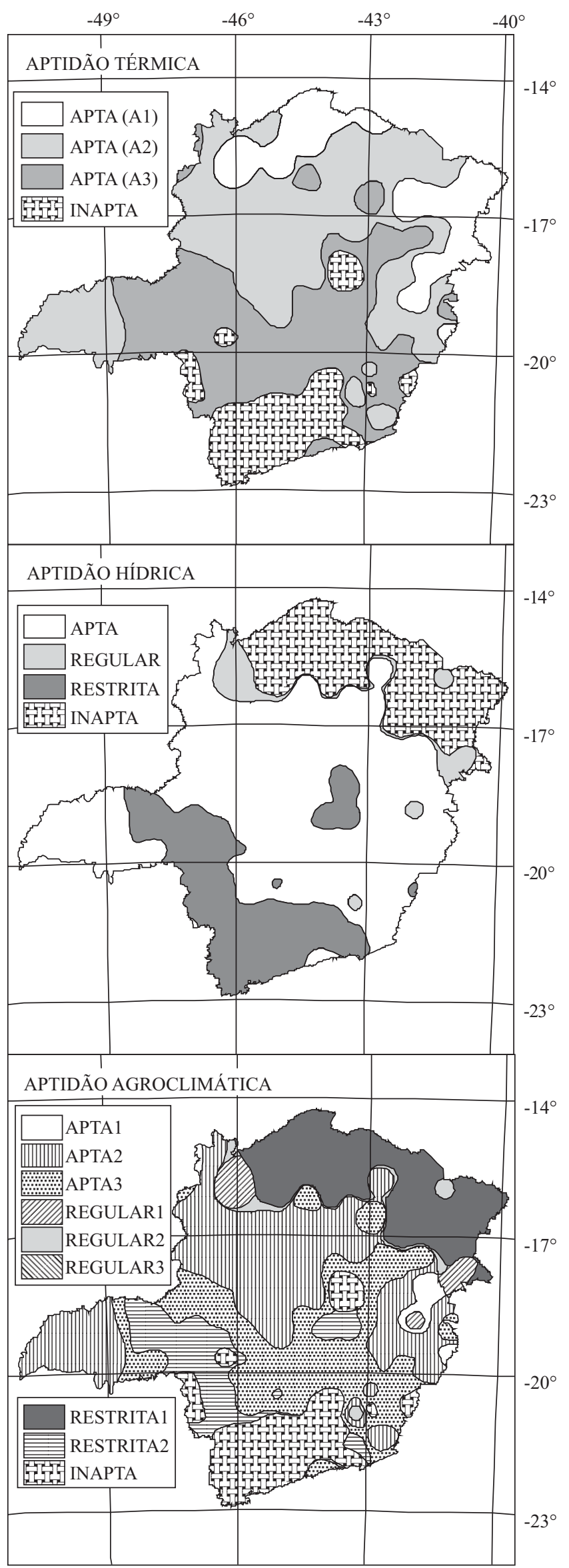

Figura 4. Aptidões térmica, hídrica e agroclimática do Estado de Minas Gerais para a cultura da acerola para a cultura da aceroleira mas que apresentam pequena ou moderada restrição térmica, é de se esperar que o crescimento e o desenvolvimento não sejam máximos, uma vez que a ocorrência de baixas temperaturas por longos períodos influencia o crescimento e o desenvolvimento das fruteiras tropicais, de modo geral (Simão, 1971).

Em condições de restrição térmicas e hídricas moderadas (área denominada regular 3, e que representa 0\% da área do estado), a aceroleira poderá apresentar crescimento inferior em comparação com cultivos presentes nas áreas de aptidão regular. Este crescimento inferior é devido, provavelmente, às baixas temperaturas noturnas durante o inverno. Ressalta-se que a ocorrência de períodos secos poderá beneficiar a cultura, uma vez que a floração é estimulada por um estresse hídrico, mas no caso da ocorrência dos períodos secos, com precipitação baixa ou nula, em momentos inadequados, tais como na fase de pleno crescimento vegetativo, o crescimento e o desenvolvimento da planta poderão ser afetados, resultando plantas pequenas ou pouco desenvolvidas e, conseqüentemente, pequena produção de frutos (Gonzaga Neto \& Soares, 1994).

As áreas inaptas ao cultivo da aceroleira se estendem ao sul do Estado, representando 12,6\% de sua área total. Nessas áreas, o cultivo não é recomendado devido à ocorrência de baixas temperaturas durante o inverno.

\section{CONCLUSÕES}

1. Apenas 12,6\% do território do Estado de Minas Gerais é inapto para o cultivo da aceroleira.

2. Em 55,8\% do Estado observam-se condições hídricas e térmicas favoráveis para o cultivo da aceroleira, sendo que somente $1,6 \%$ da área do estado apresentaram condições térmicas e hídricas ideais, 30,8\% apresentam pequena restrição térmica e ótimas condições hídricas, e 23,4\% com pequena restrição térmica e hídrica.

3. As áreas de aptidão regular ocupam, aproximadamente, $4,5 \%$ do território do Estado, sendo áreas com pequenas restrições hídricas ou térmicas.

4. As áreas que apresentam restrição hídrica ou térmica compreendem 27\% da área total do Estado, sendo que 9\% possuem restrição térmica moderada e índice de umidade elevado. Os restantes 18\% do território do estado são referentes às áreas com grandes restrições hídricas, e boas condições térmicas, sendo o cultivo, comercial, recomendado apenas com o uso da irrigação suplementar.

\section{LITERATURA CITADA}

AGRIANUAL. Anuário da Agricultura Brasileira. FNP - Consultoria \& Comércio. São Paulo, Editora Argos Comunicação, 2002. 521p.

Andrade, J. M. B.; Brandão Filho, J. V. T.; Vasconcelos, M. A. S. Efeito da poda na produtividade da aceroleira (Malpighia glabra L.) no primeiro ano. Revista Brasileira de Fruticultura, Cruz das Almas, v.17, n.2, p.45-49, 1995. 
Ansejo, C. F. Aspectos químicos y nutritivos de la acerola (Malpighia punicifolia L.). Ciência, México, v.2, n.19, p.109-118, 1959.

Antunes, F. Z. Caracterização climática de Minas Gerais. Climatologia Agrícola, Informe Agropecuário, EPAMIG, Belo Horizonte, v.12, n.138, p.9-13. 1986.

Araújo, P. S. R.; Minami, K. Acerola. Campinas, Fundação Cargil. 81p. 1994.

Assad, E. D. Sistemas de informações geográficas. Aplicações na agricultura - editado por Eduardo Delgado Assad; Edson Eyli Sano - 2. ed., revisada e ampliada - Brasília: EMBRAPA-SPI - EMBRAPA-CPAC, 1998. 434p.

Consorcio Brasileiro de Pesquisa e Desenvolvimento do Café. Zoneamento climático da cultura do café. 2002. 1 CDROM.

CEAGESP. Central de Abastecimento Agrícola do Estado de São Paulo. www.ceagesp.com.br/cotacao. 26 de junho de 2003.

Cecílio, R. A.; Medeiros, S. S.; Silva Júnior, J. L. C. Aptidão Agroclimática para o cultivo da acerola na Bahia. Bahia Agrícola. Salvador, SEAGRI, v.6, n.3, p. 20-23. 2004.

Costa, M. H. Classificação climática. Viçosa: Departamento de Engenharia Agrícola, UFV, 1994. 12p. Série Caderno Didático 18.
Gonzaga Neto, L.; Soares, J. M. Acerola para exportação: Aspectos técnicos da produção. Brasília: EMBRAPA - SPI, 1994. 43p. Série Publicações Técnicas FRUPEX 10.

Nakasone, H. Y.; Miyashita, R. K.; Yamane, G. M. Factors affecting ascorbic axid contend of the acerola (Malpighia glabra L.). Processes American Society Horticulture Science, Honolulu, v.49, p.161-166, 1996.

Pereira, A. R.; Angelocci, L. R.; Sentelhas, P. C. Agrometeorologia fundamentos e aplicações práticas. Guaíba: Livraria e Editora Agropecuária Ltda. 2002. 478p.

Simão, S. Manual de fruticultura. São Paulo: Agronômica Ceres, 1971. 530p.

Teixeira, H. C. T.; Azevedo, P. V. Potencial agroclimático do Estado do Pernambuco para o cultivo da acerola. Revista Brasileira da Agrometeorologia, Santa Maria, v.2, n.1, p.105-113, 1994.

Thornthwaite, C. W.; Mather, J. R. The water balance. Publication in climatology: Cencerton, New Jersey, v.8, n.1, 1955. 104p.

Viana, T. V. A.; Vasconcelos, D. V.; Azevedo, B. M..; Souza, V. F. Estudo da aptidão agroclimática do Estado do Piauí para o cultivo da aceroleira. Revista Ciência Agronômica, Fortaleza, UFC, v. 33, n.2, p.5-12, 2002.

Vianello, R. L.; Alves, A. R. Meteorologia básica e aplicações. Viçosa: Imprensa Universitária. 1991. 449p. 